Meta

Journal des tradlucteurs

Translators' Journal

\title{
Un sigle par-ci, un sigle par-là
}

\section{Denise Lemay}

Volume 15, numéro 1, mars 1970

La traduction religieuse

URI : https://id.erudit.org/iderudit/003461ar

DOI : https://doi.org/10.7202/003461ar

Aller au sommaire du numéro

\section{Éditeur(s)}

Les Presses de l'Université de Montréal

\section{ISSN}

0026-0452 (imprimé)

1492-1421 (numérique)

Découvrir la revue

Citer cet article

Lemay, D. (1970). Un sigle par-ci, un sigle par-là. Meta, 15(1), 42-42.

https://doi.org/10.7202/003461ar d'utilisation que vous pouvez consulter en ligne.

https://apropos.erudit.org/fr/usagers/politique-dutilisation/ 


\section{UN SIGLE PAR-CI, UN SIGLE PAR-LÀ}

À l'intention du traducteur qui regrette parfois de ne pas avoir reçu le don des sigles comme d'autres ont reçu le don des langues, voici quelques sigles, en usage au chemin de fer, glanés au fil du travail quotidien.

Certains sigles font la paire, français d'un côté, anglais de l'autre. PS (pli de service) et $\mathrm{CS}$ (colis de service) équivalent à RRB qui veut dire railroad business. $\mathrm{CCC}$, c'est la commande centralisée de la circulation, ce qui se rend en anglais par CTC ou centralized traffic control. ABS est l'abréviation d'automatic block system et se rend par CA qui vient de cantonnement automatique.

Le français possède en propre les sigles suivants : PN pour passage à niveau, BV pour bâtiment voyageurs, LRS pour longs rails soudés, PC pour poste de commande. On trouve aussi le container à $\mathrm{PA}$ ou à porteur aménagé et le dispositif de VA ou de veille automatique également appelé dispositif d'homme mort. À ces sigles correspondent en anglais les expressions suivantes : grade crossing, passenger building (of a train station), long welded rails, control tower, container with corner fittings for handling et deadman's handle.

On rencontre enfin en anglais ACI pour automatic car identification, LCL pour less-than-carload et CIP pour car information project. On les rend en français par les expressions suivantes : reconnaissance automatique des wagons, envoi, transports ou trafic de détail, selon le cas, et projet d'information wagons.

DENISE LEMAY 